\title{
Saúde Mental na Atenção Primária à Saúde: avaliação sob a ótica dos usuários
}

| ${ }^{1}$ Mara Soares Frateschi, ${ }^{2}$ Cármen Lúcia Cardoso |

Resumen: Este estudo objetivou investigar a avaliação que os usuários fazem do cuidado em saúde mental recebido por dois serviços públicos de Atenção Primária à Saúde: uma Unidade de Saúde da Família e uma Unidade Básica de Saúde. A amostra foi composta por 13 usuários de ambos os serviços, identificados pelas equipes como estando em sofrimento mental. Para a coleta de dados foi utilizado o grupo focal, sendo realizado um grupo em cada serviço. O material foi submetido à análise seguindo a abordagem qualitativa em pesquisa e utilizou-se como ferramenta a Análise de Conteúdo Temática. Os usuários apontam a necessidade de uma escuta qualificada, que promova acolhimento e vínculo, bem como de uma assistência humanizada, longitudinal e integral. Conclui-se que existe uma lacuna entre ações em saúde mental e Atenção Primária à Saúde, e que a avaliação feita pelos usuários constitui peça fundamental para o preenchimento desta brecha, uma vez que os usuários fornecem informações essenciais para a consolidação de novas formas de agir em saúde.

> Palavras-chave: Saúde Mental; Atenção Primária à Saúde; Programa de Saúde da Família; Avaliação dos Serviços de Saúde.

\author{
1 Departamento de Psicologia, \\ Universidade de São Paulo. \\ Ribeirão Preto-SP. Brasil. \\ Endereço eletrônico: \\ msfrateschi@hotmail.com \\ 2 Departamento de Psicologia, \\ Universidade de São Paulo. \\ Ribeirão Preto-SP. Brasil. \\ Endereço eletrônico: carmen@ \\ ffclrp.usp.br
}




\section{Atenção Primária à Saúde: cuidado em saúde mental}

A partir da década de 1970, as questões relativas à saúde passaram a ser amplamente debatidas em diferentes cenários e em nível internacional. Para discussão do tema, foram realizados eventos que resultaram na elaboração de documentos como a Declaração de Alma Ata, em 1978, e a Carta de Ottawa, em 1986, os quais propõem novas diretrizes para o setor da saúde, considerando a determinação social da saúde e enfatizando o processo saúde/doença (RANDEMARK, 2009; WHO, 1978; 1986).

Nesse contexto, a Atenção Primária à Saúde (APS) ganhou lugar de destaque, sendo considerada não apenas como a "porta de entrada" do usuário no sistema de saúde, mas responsável pela assistência a importantes problemas de saúde, através de ações que visam a tratamento, promoção, prevenção e reabilitação da saúde (CAMPOS et al., 2011). O cuidado ofertado nesse nível de atenção focaliza o desenvolvimento de ferramentas e conhecimentos adquiridos pelos profissionais através do contato com a comunidade (CAÇAPAVA; COLVERO, 2008).

No Brasil, o Programa de Saúde da Família configura-se como a principal modalidade de atuação da APS. Criado em 1994 pelo Ministério da Saúde, é resultado de experiências regionais do trabalho de agentes comunitários no combate à desnutrição infantil e mortalidade materna na Região Nordeste. Depois denominado Estratégia Saúde da Família (ESF), tornou-se uma política nacional do Ministério da Saúde, objetivando a reorientação do modelo assistencial, a partir da perspectiva psicossocial, tendo como pressuposto o atendimento continuado a famílias de uma área geograficamente delimitada (BRASIL, s/d.; SILVA; CARDOSO, 2013a). Nessa nova ótica, o desafio de pensar e fazer saúde pressupõe necessariamente a desconstrução da lógica de tratar apenas a doença, para tratar a pessoa com seu sofrimento no contexto da comunidade. As intervenções de saúde, portanto, devem-se pautar em uma atitude terapêutica que privilegie o cuidado, o vínculo, o acolhimento e a corresponsabilização entre profissional de saúde e usuário (MUNARI et al., 2008). Essa perspectiva propõe que o foco saia da doença e passe a ser a problemática que envolve o processo saúde/doença.

Nesse cenário de mudança de paradigma em saúde, especialmente na área da saúde mental, a APS vem ganhando destaque. Busca-se trabalhar a saúde mental no âmbito da comunidade, através da articulação entre os dispositivos de cuidado 
especializado extra-hospitalares, visando melhorar a qualidade de vida e diminuir

estigmas, através de iniciativas que busquem responder às diferentes demandas que a doença ou limitação apresentam (CAÇAPAVA; COLVERO, 2008; MUNARI et al., 2008). Silveira (2012), a partir da análise de documentos do Ministério da Saúde, observou que estes preconizam, entre outros aspectos, que os serviços da rede básica assistam à demanda de saúde mental, propiciando a inserção da pessoa na comunidade, em contraposição à segregação causada pelo hospital psiquiátrico. Os documentos também enfatizam a integração dos serviços de saúde entre si, bem como a integração destes com os demais equipamentos sociais.

Reinaldo (2008) elenca algumas características atribuídas às ações da APS quanto ao cuidado da saúde mental: estar associada às demais ações da rede básica; assegurar o bem-estar da comunidade e do indivíduo; privilegiar as açōes preventivas, individuais e coletivas; alocar os programas de saúde mental em diferentes serviços da rede básica, formando uma rede de suporte; realizar ações diretas e indiretas; utilizar novas estratégias de abordagem em saúde; agregar profissionais com diferentes formações, implicar a comunidade e, por fim, considerar as características da comunidade.

Dessa forma, se for levado em conta que as pessoas em sofrimento mental necessitam de cuidados básicos de saúde e que o SUS preconiza a desinstitucionalização e a assistência humanizada, a APS se torna importante estratégia para a (re)inserção dessas pessoas na sociedade (ARCE; SOUSA; LIMA, 2011; SILVA; CARDOSO, 2013b). A parceria entre a saúde mental e a APS se torna, portanto, benéfica e necessária, pois articula os desafios da Reforma Psiquiátrica com a responsabilização das equipes que atuam nesse nível de assistência (DELFINI et al., 2009).

\section{Avaliação dos serviços de saúde sob a ótica dos usuários}

No campo da Saúde Pública, a avaliação de serviços é de extrema relevância, pois viabiliza o planejamento e possibilita um controle técnico e social dos serviços e programas prestados à sociedade (DESLANDES, 1997). Para Silva e Formigli (1994), a avaliação de serviços de saúde deve aferir não só a efetividade técnica, mas também a efetividade psicossocial, a qual seria dada pela satisfação de usuários e profissionais. 
A avaliação realizada por usuários e por seus familiares tem papel importante na promoção da qualidade dos serviços, uma vez que fornece informações pertinentes sobre a qualidade do atendimento e os resultados do tratamento (COSTA et al., 2011). Para Donabedian (2003), as ponderaçōes feitas pelos usuários são fundamentais na avaliação em saúde, uma vez que, neste caso, o julgamento da qualidade é mesclado com expectativas e percepções. Nesse sentindo, a satisfação ou insatisfação do usuário representa um reflexo do cuidado oferecido pelo serviço.

Para Brandão, Giovanella e Campos (2013), a satisfação é um processo dinâmico que sofre influências de fatores como a percepção da condição de saúde, crenças e características sociodemográficas, relacionando conteúdos que carregam expectativas individuais e coletivas, bem como fatores econômicos, políticos e culturais. Assim, as informações advindas da avaliação dos usuários quanto aos serviços de saúde podem fomentar melhorias do atendimento. O crescente interesse por essa temática está atrelado à compreensão do usuário como provedor de informaçôes confiáveis e adequadas, essenciais para completar e equilibrar a qualidade dos serviços. Nesse sentido, no contexto da APS, a percepção dos usuários é de extrema importância, uma vez que a comunidade é a razão da existência desse serviço e deve ser identificada como capaz de avaliar e intervir, modificando as práticas em saúde (TAHAN-SANTOS; CARDOSO, 2008).

No âmbito da saúde mental, em decorrência da transformação do modelo assistencial, surge a necessidade de se criar metodologias de avaliação dos serviços implementados, uma vez que as modificaçōes propostas não vieram acompanhadas de uma avaliação sistemática. É importante saber se há, de fato, promoção de mudanças na qualidade de vida dos usuários e se os serviços estão comprometidos com os interesses desses sujeitos sociais no exercício de sua cidadania (JAEGGER et al., 2004).

De acordo com Costa et al. (2011), a avaliação de serviços de saúde mental deve ser uma atividade contínua, realizada com o propósito de identificar aspectos da assistência aos usuários que necessitam ser reajustados e promover melhorias do tratamento oferecido e da qualidade dos serviços. Para Jaegger et al. (2004), a avaliação dos usuários se torna especialmente importante à medida que se vivencia a transformação do modelo de atenção, redirecionando o modelo baseado na internação hospitalar para as diversas alternativas de assistência na comunidade. 
Este trabalho objetivou investigar a avaliação que os usuários fazem do cuidado em saúde mental ofertado pelo serviço de APS ao qual recorrem. Especificamente, buscou-se investigar expectativas, experiências e satisfação dos usuários com relação ao cuidado que recebem e, ainda, comparar a assistência ofertada pelos diferentes serviços. O estudo foi realizado numa Unidade Básica de Saúde (UBS) e numa Unidade de Saúde da Família (USF) de um município de médio porte localizado no interior do estado de São Paulo.

\section{Método}

Foi adotada a abordagem qualitativa em pesquisa (MINAYO, 2012), utilizandose o método de Análise de Conteúdo Temática como instrumento para análise dos dados. Para Bardin (2011, p. 48), o método consiste num

[...] conjunto de técnicas de análise da comunicação visando obter, por procedimentos sistemáticos e objetivos de descrição do conteúdo das mensagens, indicadores que permitam a inferência de conhecimentos relativos ao modo como tais mensagens foram produzidas, transmitidas e recebidas.

A Análise de Conteúdo Temática é composta por três etapas, a saber: a) Préanálise: consiste na leitura flutuante dos textos, tomando contato exaustivo com o material e seu conteúdo; b) Exploração do material: trata-se, essencialmente, da codificação do material pesquisado, através de recortes, agregação e enumeração, permitindo atingir uma representação do conteúdo capaz de esclarecer o analista acerca das características do texto; c) Tratamento dos resultados e interpretação: consiste na categorização dos resultados brutos e realização de inferências a partir dos recortes e agrupamentos elaborados.

Para análise dos dados, realizou-se um diálogo com os autores da Saúde Coletiva e da Saúde Mental, visando situar o estudo em relação ao campo de conhecimento no qual se insere, localizando suas bases teóricas e possibilidades de contribuições.

\section{Escolha das unidades e seleção dos participantes}

A USF foi selecionada levando-se em consideração a disponibilidade da equipe em aceitar a pesquisa e o histórico da unidade, a qual deveria atuar de acordo com os princípios da ESF, nunca tendo funcionado como UBS tradicional. Já os critérios para escolha da UBS incluíam a disponibilidade da equipe, a presença de 
um médico generalista na equipe e a ausência de equipe da ESF ou da Estratégia de Agentes Comunitários de Saúde.

Os usuários da USF foram selecionados a partir de indicação dos profissionais da equipe. Foi realizada consulta aos prontuários dos usuários indicados, a fim de verificar, caso a caso, a pertinência do convite para participação no estudo. Já as indicaçõos de usuários da UBS foram conseguidas através de um serviço ambulatorial especializado em saúde mental, uma que vez que foi constatado que a unidade não possuía controle, como registros ou listagens, das pessoas que recorriam àquele serviço com queixa de sofrimento mental. Através do serviço ambulatorial, foi possível identificar as pessoas que recorreram à UBS com queixa de sofrimento mental e foram encaminhadas para o serviço especializado.

Para estarem aptos a participar da pesquisa, os usuários deveriam preencher os seguintes critérios: possuir 18 anos completos ou mais e ser reconhecido pela equipe como estando em sofrimento mental. No caso da USF, o usuário deveria, ainda, ser cadastrado no serviço e ter registrado em seu prontuário o diagnóstico de transtorno psiquiátrico.

\section{Procedimento de coleta de dados: grupo focal}

Para coleta de dados, foram realizados dois grupos focais, sendo um em cada serviço, de forma que cada usuário participou de apenas um grupo. O grupo focal realizado na USF contou com a participação de seis usuários, sendo um homem e cinco mulheres, com idades entre 24 e 75 anos. O grupo focal na UBS teve sete participantes, todas do sexo feminino e com idades variando entre 26 e 56 anos. Um roteiro de entrevista foi elaborado com a finalidade de orientar a discussão em grupo, pontuando os tópicos a serem abordados durante o encontro.

Todos os participantes assinaram o Termo de Consentimento Livre e Esclarecido (TCLE), aceitando participar voluntariamente do estudo. Os grupos foram audiogravados e tiveram duração de aproximadamente duas horas cada um. Posteriormente, o áudio dos encontros foi transcrito na íntegra e literalmente.

O presente estudo foi aprovado pelo Comitê de Ética em Pesquisa do Centro de Saúde Escola da Faculdade de Medicina de Ribeirão Preto da Universidade de São Paulo (Protocolo n 394/CEP-CSE-FMRP-USP), e teve como princípio a adoção dos procedimentos básicos e éticos de respeito aos voluntários e à 
instituição, de acordo com a Resolução n 466/12 do Conselho Nacional de

Saúde sobre pesquisa envolvendo seres humanos (BRASIL, 2012).

\section{Resultados e Discussão}

A partir da análise das transcrições, foram construídas quatro categorias temáticas, a saber: "Pontos Fortes", "Pontos Frágeis", "Sugestōes" e "Concepçōes", as quais apresentam a avaliação dos usuários acerca do cuidado em saúde mental recebido. Para apresentação das categorias, visando maior visibilidade e compreensão, foram utilizados trechos dos grupos focais.

\section{Pontos Fortes}

Esta categoria apresenta os aspectos da assistência à saúde mental avaliados pelos usuários como satisfatórios. Os participantes, baseados em suas próprias experiências, necessidades e expectativas, relataram situações em que recorreram ao serviço com queixa de sofrimento mental e receberam o Apoio e o Acompanhamento que julgaram necessários.

Esse ano, em fevereiro, morreu um neto meu de acidente com 18 anos. [...] Então, naquele momento eu senti que eu ia ter... Ai! (suspiro) Sabe? Foi difícil, chorei muito, botei tudo pra fora, nossa! [...] Eu corri pros braços das meninas aqui, corri lá pro Dr. Mário, "Ah, doutor, me ajuda!" (Participante 05 - USF)

Quando eu chego aqui, eu já chego até chorando, eles já sabem, já correm com tudo, e eu agradeço muito a eles, deles me vê quando eu to chegando esquisita, eles já correm comigo. (Participante 03 - USF)

Observa-se, a partir do relato da participante 05, que a USF foi identificada como um local de apoio quando a usuária precisou de suporte imediato. Já a partir do relato da participante 03 , nota-se que a equipe da USF, em decorrência do acompanhamento que realizava desta usuária, já possuía um conhecimento prévio acerca de sua condição. Acredita-se que tal conhecimento foi útil para nortear as decisões da equipe quanto aos procedimentos mais adequados a serem realizados com relação a esta usuária quando ela "chegou esquisita" (sic) buscando ajuda do serviço.

Para Cecílio (2001), uma das maneiras de apreender as necessidades de saúde apresentadas pelos usuários é através do estabelecimento de vínculos (a)efetivos entre os mesmos e as equipe e/ou profissionais. A oportunidade de estabelecer 
relações de proximidade e confiança possibilita que o serviço seja identificado e reconhecido como referência para os cuidados em saúde. A partir dos relatos das participantes, nota-se que, de maneira geral, os usuários apontaram a USF como um local onde se obtém ajuda em situações de necessidades específicas, bem como reconheceram que tal serviço exerce um acompanhamento contínuo de suas condiçōes. Assim, nestes casos, observa-se que a equipe da USF interviu em favor do bem-estar das usuárias, proporcionando o suporte que elas foram buscar no serviço de saúde. Entretanto, cabe a ressalva de que em ambos os relatos a atuação da equipe esteve atrelada a uma situação de urgência ou agudização do sofrimento e, nesse contexto, pode-se inferir que se trata de um processo de transformação na área da saúde e que a maior proximidade com os usuários e suas famílias pode propiciar o desenvolvimento de estratégias mais efetivas, que respondam as necessidades dos usuários e não só as suas demandas emergenciais (CECÍLIO, 2001).

Esta categoria contempla apenas os usuários da USF, dado que as usuárias da UBS não relataram situações em que julgaram ter recebido o apoio e o acompanhamento desejados.

\section{Pontos Frágeis}

Esta categoria aborda os aspectos dos serviços avaliados pelos participantes como insatisfatórios. Os usuários de ambas as unidades relataram situações em que identificaram Falta de apoio no que diz respeito às demandas relativas à saúde mental.

Você não pode chegar aqui e falar "Ô bem, eu não estou legal". Você não tem aquela liberdade. [...] Eu não tenho coragem de chegar nas meninas aqui e falar "Ah, eu não tô bem! Eu tô com voz... eu tô ouvindo vozes, eu vou me matar, eu vou...” (Participante 04 - USF)

Então você vê que não tem respaldo nenhum à saúde mental, aqui, nesse postinho, não tem! Nenhum! Nada, nada, nada. [...] É assim: você vem, é receita pra seis meses e pronto. E vai de seis em seis. Você, então, resumindo, você vem duas vezes por ano; só pra pegar receita. Aí vai rolando... Você vem seis meses, pega, vem seis meses nã nã nã... Aí vai, dois, três anos, quantos anos você ficar quieta tomando aquele remédio. (Participante A - UBS)

As vinhetas acima ilustram a insatisfação dos usuários com relação à maneira como foram recebidos pelas equipes quando recorreram aos serviços com 
queixas de sofrimento mental. Infere-se que os profissionais não se aproximaram suficientemente destas pessoas a ponto de investigar suas necessidades e investir no fortalecimento do vínculo. Após algumas experiências em que recorreram aos serviços e não se sentiram acolhidos, os usuários concluíram que os profissionais não estavam qualificados para recebê-los e, consequentemente, não eram capazes de atender suas demandas.

As usuárias da UBS se queixaram da Falta de responsabilização dos profissionais frente às queixas de sofrimento mental, enfatizando a desarticulação das ações e serviços, conforme pode ser observado no relato abaixo:

Aí, se chega uma hora e ele (o médico) vê que você piorou... Ele vê, não! Você que fala, né? Porque eles não vêem nada. Você que tem que falar "Ó, doutor, eu piorei, né?”. Aí ele cata e dá o encaminhamento lá pro (serviço ambulatorial especializado). (Participante A - UBS).

As participantes relataram certo abandono, uma vez que são repetidamente redirecionadas a outras unidades de saúde, sob os cuidados de outros profissionais, sem que nenhum serviço ou profissional se responsabilize pelo acompanhamento da situação. De modo geral, os usuários acabam não se vinculando a nenhum serviço, independentemente do nível de assistência, de forma que ficam sem uma referência para suas necessidades em saúde mental.

Os usuários de ambos os serviços, pautados em suas compreensões acerca dos processos e estratégias de cuidado, avaliaram que os profissionais desempenham uma Atuação excessivamente pautada da dimensão biológica dos indivíduos. $\mathrm{O}$ trecho a seguir ilustra essa compreensão:

Sabe, também depende do médico ser inteligente e ir testando os medicamentos e conversando com a pessoa, numa ação conjunta. Não aquela coisa "só vou te dar remédio e pronto" e, sei lá, ir conversando, perguntando, acompanhando a medicação, vendo se realmente o remédio tá surtindo efeito, e, caso não esteja, ir testando os remédios até achar um com o qual a pessoa se dê melhor. (Participante 02 - USF)

Observou-se, a partir dos relatos, que ambos os serviços desenvolvem uma atuação cujo foco incide em intervenções centradas na consulta médica, na medicalização, no diagnóstico, visando à remissão dos sintomas. Nesse sentido, os participantes ressaltaram a necessidade de maior proximidade, de maior diálogo entre usuário e profissional, uma vez que se consideram agentes ativos de seu processo saúde/doença, capazes de fornecer informações relevantes acerca de sua condição e de intervir conjuntamente com os profissionais em favor de sua saúde. 
Os usuários também evidenciaram suas percepções sobre o cuidado em saúde mental ofertado pelos serviços não especializados, enfatizando o Preconceito e a discriminação que ainda permeiam essas demandas.

Não é aqui, é que todo lugar, assim, que não é dito especializado em saúde mental, ele não entende um estigma. (Participante 02 - USF)

Segundo os participantes, os usuários que recorrem com queixa de sofrimento mental, principalmente a serviços não especializados, são constantemente vítimas de preconceito e discriminação. Percebe-se certa dificuldade dos profissionais em ampliar o olhar sobre a pessoa em sofrimento mental, de forma a enxergá-la em sua integralidade, digno de respeito, cuidado e atenção.

A partir das vinhetas que ilustram esta categoria e considerando o campo da Saúde Coletiva brasileira, observa-se que os participantes se mostraram insatisfeitos com alguns aspectos importantes do cuidado recebido, evidenciando situações em que não reconhecem o serviço como um local de referência para o cuidado da pessoa em sofrimento mental. Nesse sentido, considerando que a opinião dos usuários carrega informações importantes acerca da qualidade do atendimento e dos resultados do tratamento (BRASIL, 2010; COSTA et al., 2011), evidenciase a importância da participação social nos processos de produção do cuidado, possibilitando maior correspondência entre a oferta dos serviços e as necessidades dos usuários. Carvalho e Gastaldo (2008) sugerem o exercício de uma prática profissional que se baseia na compreensão do usuário enquanto cidadão, portador de direitos, capaz de estabelecer parcerias com os profissionais, contribuindo para a construção de práticas de saúde mais integrais e simétricas.

\section{Sugestôes}

Esta categoria se refere às sugestôes apontadas pelos usuários, visando a um melhor atendimento por parte dos serviços de saúde. Os participantes indicaram que a Longitudinalidade do cuidado é um aspecto importante a ser considerado pelos serviços da APS.

Não tem, não tem, assim, um acompanhamento, nada, nada. [...] porque a pessoa fica seis meses tomando remédio sem saber se tá bom ou se não tá, se tá fraco ou se tá forte, se tá... (Participante A - UBS).

As participantes da UBS apontaram para a necessidade de um acompanhamento mais próximo e continuado por parte dos profissionais, que 
levasse em consideração a pessoa e seu sofrimento, para além da doença, do seu diagnóstico e tratamento. Para Starfield (2002), a longitudinalidade está associada a um melhor reconhecimento de problemas, melhor entendimento e participação dos usuários, o que resulta em menos dias de incapacitação e desconforto. A falta de acompanhamento é desfavorável ao tratamento, uma vez que o profissional não se corresponsabiliza pelo cuidado do usuário, que acaba por assumir praticamente sozinho o peso de seu sofrimento.

Outra proposta dos usuários consiste na Inclusão de profissionais especializados, conforme pode ser observado nas vinhetas abaixo:

Elas (profissionais da USF) não são especializadas pra tratar aqui. Tinha que ser a pessoa da área, já que tem psiquiatria... [...] Só que então tem que ter a pessoa preparada. (Participante 04 - USF)

Eu acho que todos os postinhos podia ter um grupo de terapia. Nem que entrassem numa listinha de espera. (Participante B - UBS)

Os participantes da USF propuseram que fossem incluídos profissionais especializados em saúde mental à equipe da unidade, o que na visão dos mesmos melhoraria a qualidade do serviço oferecido. A participante 04 sequer cogita que esse cuidado possa ser feito por profissionais que não sejam especializados, uma vez que, baseada em suas experiências, não teve sua necessidade acolhida pela equipe da USF. Já na UBS, as participantes sugeriram a inclusão de psicólogos na equipe e a criação de grupos de terapia no serviço. Para elas, estes grupos seriam espaços onde as pessoas poderiam conversar, conviver, trocar experiências, dividir momentos difíceis. Estas atividades diversificariam a atenção oferecida pela UBS, até então centrada nas práticas médicas.

Franco e Merhy (2012), considerando o atual debate em torno da mudança do modelo tecnoassistencial em saúde, ressaltam a natureza relacional do trabalho em saúde, atribuindo lugar de destaque ao trabalho vivo em ato. Os autores apontam que apesar do trabalhador da saúde dispor de certo grau de liberdade, muitas vezes acabam capturados pela mecanicidade do cotidiano, impelidos a reproduzir a lógica centrada no ato prescritivo, alto consumo de insumos e procedimentos.

Assim, observa-se que, frequentemente, as estratégias mais horizontais e relacionais são tratadas como meros detalhes dos processos de cuidado, fragmentando as ações em saúde. De acordo com Merhy (2002), os profissionais deveriam ser capacitados para atuarem no âmbito das tecnologias leves, o que 
implica a produção do acolhimento, responsabilização e vínculo. Neste sentido, ressalta-se que as ações de cuidado à saúde mental poderiam ter como foco a elaboração de projetos terapêuticos e comunitários que pudessem reconhecer e acolher as queixas de sofrimento mental, intervindo em favor da saúde dos usuários e da comunidade.

Os participantes de ambos os grupos sugeriram, ainda, que os serviços desenvolvessem Atividades de promoção de saúde. Foram citados exemplos de atividades que promovessem a convivência, a integração com membros da equipe e da comunidade, a realização de trabalhos manuais, a organização de feiras, bazares, grupos de ginástica, entre outros.

Eu vinha mais porque eles ensinavam a bordar aqui [...] A gente fazia o bazar do ano, do meio do ano. [...] mas agora, nunca mais teve. [...]. Eu falo pra Patrícia (enfermeira da USF): "Patrícia, vamos fazer aqui alguma coisa." E ela fala "Ah, estou esperando a senhora, estou esperando a senhora." (Participante 06 - USF).

É, tipo uma prevenção mental, né, vamos falar entre aspas, né? Porque você não previne, assim, contra a hipertensão reduzindo o sal, certo? Se a pessoa se previne de um diabetes diminuindo o açúcar e por aí vai, não é?” (Participante A - UBS).

As participantes da UBS desenvolveram em conjunto a ideia de um grupo de "prevenção mental" (sic). Sugeriram a organização de um mutirão que realizasse um mapeamento do bairro, visando identificar a demanda por atividades de promoção e prevenção. Segundo elas, este levantamento seria útil para organização das atividades quanto à quantidade de grupos, número de encontros e horários.

Dentre às atividades que competem à APS estão as de promoção de saúde, cuja ênfase é justificada pela efetividade de custos das mesmas, por possibilitarem que comunidades e indivíduos tenham mais controle sobre sua própria saúde, incentivando a autonomia, e por serem essenciais para combater os determinantes sociais do processo saúde/doença (BRASIL, s/d.; TAHAN-SANTOS; CARDOSO, 2008).

As participantes da UBS também apontaram para a Necessidade de mais recursos no território, sugerindo que os serviços próximos às suas residências estejam suficientemente preparados para o cuidado em saúde mental.

Eles mandam a gente pra outro lugar. E como que a gente vai? E quem não tem carro? E tem que ficar dependendo de ônibus? [...] Então, agora, pra quem depende de pessoas pra levar e buscar, que não sabem andar de ônibus, como eu, né. Eu não sei andar de ônibus; eu não sei. [...] Por isso que eu falei do tratamento que é necessário aqui. Porque uma que é mais perto, eu tenho como, a gente tem como vim. (Participante G - UBS). 
As participantes do grupo na UBS não identificaram a unidade como referência para o cuidado à saúde mental. Afirmaram que recorrem a este serviço como uma alternativa de ajuda, entretanto avaliaram que não recebem uma atenção continuada, de forma compromissada. Infere-se que a UBS tenha realizado o encaminhamento das usuárias para o serviço especializado sem que fosse explorado o leque de ações que compete a esse nível de atenção. $\mathrm{O}$ serviço especializado, por sua vez, indicou que as usuárias tentassem acompanhamento psicológico nas clínicas-escola dos cursos de Psicologia do município, as quais, todavia, distam muito de suas residências. Como consequência, tem-se uma situação em que pacientes necessitados de ajuda circulam pelos serviços sem receber a devida assistência.

Vale ressaltar que a necessidade de mais recursos no território não foi uma questão abordada pelos participantes da USF. Nesse sentido, infere-se que a USF consiga ofertar um cuidado relativamente mais humanizado, visando à criação de vínculos com a comunidade.

Considerando esta categoria, observa-se que o posicionamento dos usuários corrobora o preconizado pelas Reformas Sanitária e Psiquiátrica no que diz respeito à necessidade das ações no âmbito da APS transcender a doença e os sintomas, e se comprometer com a pessoa, visando à continuidade de seu percurso de vida, desenvolvendo e criando continuadamente novas possibilidades de lidar com o sofrimento humano (TANAKA; RIBEIRO, 2009; BRASIL, 2005; DIMENSTEIN et al., 2009; SILVA; CARDOSO, 2013a).

\section{Concepções}

Esta categoria aborda a compreensão dos usuários sobre temas como saúde mental, pessoa em sofrimento, serviço de saúde e cuidado. Tais concepções são construídas com base nas experiências, expectativas e desejos de cada pessoa no decorrer de seu processo saúde/doença. O conhecimento destas concepções é importante para o entendimento do julgamento dos usuários acerca da assistência que recebem.

A doença nossa, é a na pele? É! É na carne? É! Mas, muito ajuda essa doença, aqui ó (aponta a cabeça). É muita preocupação que você tem; é a vida que você leva, entendeu? [...] Você vai no clínico geral ele só pode te dar o remédio [...] O meu caso é terapia. (Participante G - UBS). 
Eu brinco com meu médico, falo assim "Eu não quero ficar louca" e ele fala "Você não vai ficar porque você fala que você não quer ficar louca”. [...] Não tem nada de louca. Hoje não é. Simplesmente doente mental precisa de ajuda, de carinho e de amor. [...] Então é isso, então nós não somos, nenhum de nós, não existe mais loucura, existe necessidade de uma ajuda." (Participante 05 - USF).

"Não, tsc tsc, é um absurdo! Eu não vou deixar essa doença me dominar! Eu não vou! De jeito nenhum!” Levantei rapidinho, troquei de roupa e vazei pra cá. Então, assim, tem que lutar porque senão a doença toma conta mesmo. Se você for se entregar, eu ficaria em casa mesmo. Deitada, deprimida. Porque se eu não consigo levantar pra fazer as coisas, eu fico deprimida. (Participante A - UBS).

Só que dos últimos anos pra cá que, tipo, teve uma maior conscientização, aí, tipo, que as pessoas parece que ficaram mais ligadas, sabe? Mas aí não pode mais bater, espancar o cara, dar choque, fazer o que quiser porque... ficaram mais receosos. (Participante 02 - USF).

Hoje não existe mais hospital de louco, hoje existe atendimento a doente mental. (Participante 05 - USF).

Os participantes demonstraram compreender que cada indivíduo está inserido em seu próprio contexto familiar, social e cultural; sendo composto não apenas por aspectos biológicos, mas, também, por aspectos psicológicos e sociais. Nesse sentido, compreende-se a pessoa em sofrimento mental como completa, inteira, e que não se reduz apenas a um diagnóstico. Os profissionais, ao reduzirem seu potencial de intervenção à doença, se limitam a receitar medicamentos, ao passo que, se atuassem considerando a integralidade do indivíduo, poderiam investir no fortalecimento do vínculo, desempenhando uma escuta ativa e interessada de suas necessidades de saúde, contribuindo para que os usuários se percebam acompanhados.

Os participantes demonstraram, ainda, que compreendem a pessoa em sofrimento mental como alguém capaz de ser protagonista de seu processo saúde/doença. A concepção de usuário passivo e incapaz de expressar opiniões é substituída por uma concepção de usuário capaz de avaliar o que recebe, provendo informações confiáveis e úteis. Corroborando Costa et al. (2011), o usuário, de acordo com este novo conceito, é inserido no âmbito das decisões do que lhe diz respeito, atuando em favor de sua saúde juntamente com os profissionais e a equipe.

Por fim, os participantes demonstraram compreender que o modelo assistencial está em transformação. Afirmaram que a atuação do serviço deve ser mais ampla do que apenas desempenhar atividades técnicas e com fins curativos. Enfatizaram a necessidade da oferta de uma escuta qualificada, capaz de receber o usuário em 
seu sofrimento, a fim de que as pessoas se sintam acompanhadas e considerem a

unidade de saúde como referência para o cuidado de sua saúde mental.

\section{Considerações finais}

Pode-se notar que os participantes se posicionaram diante do cuidado que recebem e explicitaram suas experiências, expectativas e percepções acerca dos serviços. Tais informações são relevantes, uma vez que carregam conteúdos individuais e coletivos, permeados por fatores econômicos, sociais, políticos e culturais.

Os usuários, em consonância com os princípios e diretrizes do SUS, apontaram que a saúde é conquistada não apenas com a remissão dos sintomas, mas também através da possibilidade de partilhar com a equipe de saúde o processo saúde/doença vivenciado, de forma a viabilizar relações de cuidado mais integrais e simétricas. Para tanto, de acordo com os próprios usuários, o foco de atuação dos serviços deve sair da doença e passar a ser a pessoa, composta por suas múltiplas dimensōes e inserida no seu contexto familiar, social e cultural. Enfatizaram que o ato de cuidar não se resume a ministrar medicamentos e a emitir encaminhamentos, mas deve implicar o fortalecimento dos vínculos, de forma que os profissionais estejam qualificados para se corresponsabilizarem pelas situações de sofrimento mental, atuando de maneira ativa e comprometida e visando a continuidade do cuidado.

Observou-se uma tendência à medicalização dos sintomas e consequente redução do indivíduo ao seu aspecto biológico. A conduta pautada em procedimentos técnicos, centrada na cura e na hierarquia dos saberes, regida pelo modelo médico-hegemônico, acaba por distanciar o profissional do usuário, enquanto pessoa em sofrimento. Nesse contexto, infere-se que os profissionais apresentam dificuldade para atuar frente a demandas que não são físicas e acabam encaminhando os usuários para serviços especializados, desresponsabilizandose pela situação. Os usuários, por conseguinte, ficam circulando pelos serviços, muitas vezes sem reconhecer nenhum deles como referência de cuidado.

Através dos relatos dos participantes, pode-se perceber uma lacuna entre ações de saúde mental e APS. Apesar de as diretrizes da Política Nacional de Saúde Mental preverem uma série de ações exequíveis nesse nível de assistência, os usuários referem ser quase que automaticamente encaminhados aos serviços especializados (BRASIL, 2010; 2001). Nesse sentido, percebe-se que além da 
necessidade de criação de novos recursos, necessita-se que os recursos existentes sejam mais bem explorados, visando oportunizar uma participação mais ativa do usuário, tanto dentro do serviço, quanto dentro de seu próprio processo saúde/ doença. Vale ressaltar que os usuários demonstraram estar preparados para integrar espaços de discussão e de troca, visando a corresponsabilização pelos fazeres em saúde.

As sugestóes dos usuários para um melhor atendimento se aproximam do que já é preconizado pelos princípios e diretrizes do SUS, ou seja, um cuidado longitudinal, integral e humanizado, pautado em práticas de promoção de saúde e prevenção de agravos, de base fundamentalmente comunitária, com profissionais qualificados para oferecer cuidados à saúde mental. A necessidade de maior articulação dos serviços em rede está de acordo com o que demanda a realidade epidemiológica atual, em que se constata uma epidemia das condiçõos crônicas (MENDES, 2011). De acordo com os relatos, a prática dos serviços de saúde encontra-se fragmentada, o que se torna um obstáculo para a prestação de uma assistência continuada aos usuários que apresentam uma condição crônica. Conforme propõe o Ministério da Saúde (BRASIL, 2010), a expansão da ESF e a consequente implantação dos Núcleos de Apoio à Saúde da Família (NASF) são alternativas para que sejam evitados os encaminhamentos indiscriminados dos usuários para os serviços especializados, visando aumentar a capacidade resolutiva da equipe local. Dessa forma, prioriza-se que os usuários recebam atenção em seu território. Ressalta-se, portanto, a importância da ampliação da área de cobertura da ESF e a efetiva implantação dos NASF, uma vez que esta é a proposta do Ministério da Saúde para a APS e, como pode ser visto neste estudo, ela corresponde às expectativas e necessidades dos usuários com relação ao serviço de saúde.

No que diz respeito à comparação entre os serviços estudados, a partir das avaliaçôes feitas pelos usuários de ambos, nota-se que existem algumas diferenças que acabam por distingui-los. Na USF, observoaram-se melhor padrão de registro dos dados dos usuários; vínculo mais evidente entre equipe e usuário; e maior índice de identificação do serviço como local de ajuda. Na UBS observaram-se, de acordo com os participantes, um padrão de encaminhamentos dos usuários para serviços especializados e uma desresponsabilização pelo acompanhamento das situações de sofrimento mental. Infere-se que a USF, em relação à UBS, 
tem atuação mais próxima da preconizada pelo SUS, de maneira que parece se encontrar mais afinada com o processo de transformação do modelo assistencial, focado numa perspectiva psicossocial. Entretanto, as avaliações não divergiram significativamente no que diz respeito às práticas pautadas no modelo médico, visando a cura, falta de profissionais qualificados para atender à demanda de saúde mental, ausência de oferta de atividades de promoção de saúde e necessidade de continuidade do cuidado.

Considera-se como limitação do presente estudo que o mesmo representa um recorte da situação da oferta de ações de saúde mental em nível da APS, circunscrita a duas unidades de saúde de um município de médio porte. Apesar disso, considera-se que o mesmo possibilitou uma reflexão acerca das potencialidades da APS no que diz respeito aos cuidados à saúde mental, bem como acerca da importância da participação ativa dos usuários em seu processo de tratamento. Os resultados discutidos, embasados nos relatos dos usuários, apontam para questóes relevantes que podem servir como norteadoras de políticas públicas de saúde mental. O estudo evidenciou o potencial do usuário para participar dos processos de decisão acerca de sua saúde, bem como de avaliar o serviço que frequenta e o cuidado que recebe.

Novos estudos são necessários visando ampliar as questões abordadas e, nesse contexto, sugere-se que seja investigada a perspectiva dos profissionais acerca da assistência à saúde mental oferecida no nível da APS, a fim de se desenvolver uma compreensão bilateral da situação. Conclui-se que a continuidade dos processos de avaliação dos serviços de saúde segundo a perspectiva dos usuários pode auxiliar a (re) estruturação dos serviços de saúde, na tentativa de melhor adequálos às necessidades dos usuários, de forma a contribuir para a construção de novas modalidades de agir em saúde. ${ }^{1}$

\section{Referências}

ARCE, V.A.R.; SOUSA, M.F.; LIMA, M.G. A práxis da saúde mental no âmbito da Estratégia Saúde da Família: contribuições para a construção de um cuidado integrado. Physis: Revista de Saúde Coletiva. Rio de Janeiro, v. 21, n. 2, p. 541-560, 2011.

BARDIN, L. Análise de conteúdo. Lisboa: Edições 70, 2011.

BRANDÃO, A.L.R.B.S.; GIOVANELLA, L.; CAMPOS, C.E.A. Avaliação da atenção básica pela perspectiva dos usuários: adaptação do instrumento EUROPEP para grandes centros urbanos brasileiros. Ciência \& Saúde Coletiva. Rio de Janeiro, v. 18, n. 1, p. 103-114, 2013. 
BRASIL. Lei no 10.216, de 06 de abril de 2001. Dispõe sobre a proteção e os direitos das pessoas portadoras de transtornos mentais e redireciona o modelo assistencial em saúde mental. Disponível em: < http://www.planalto.gov.br/ccivil_03/leis/leis_2001/110216. htm>. Acesso em: 14 maio 2014.

BRASIL. Ministério da Saúde. Conselho Nacional de Saúde. Resolução no 466/12, de 12 de dezembro de 2012. Aprova diretrizes e normas regulamentadoras de pesquisa envolvendo seres humanos. Diário Oficial [da] República Federativa do Brasil, Poder Executivo, Brasília, DF, 13 jun 2013. Seção 1, p. 59.

BRASIL. Ministério da Saúde. Departamento de Atenção Básica. Atenção Básica e Saúde da Família. s.d. Disponível em: <http://dab.saude.gov.br/atencaobasica.php>. Acesso em: 14 maio 2014.

BRASIL. Ministério da Saúde. Reforma Psiquiátrica e política de Saúde Mental no Brasil. Conferência Regional de Reforma dos Serviços de Saúde Mental: 15 anos depois de Caracas. Brasília: Ministério da Saúde, 2005.

BRASIL. Ministério da Saúde. Secretária de Atenção à Saúde. Departamento de Atenção Básica. Diretrizes do NASF: Núcleos de Apoio à Saúde da Família. Brasília: Ministério da Saúde, 2010 (Cadernos de Atenção Básica, v. 27).

CAÇAPAVA, J.R.; COLVERO, L.A. Estratégias de atendimento em saúde mental nas Unidades Básicas de Saúde. Revista Gaúcha de Enfermagem. Porto Alegre, v. 29, n. 4, p. 573-580, 2008.

CAMPOS, R.O. et al. Saúde mental na atenção primária à saúde: estudo avaliativo em uma grande cidade brasileira. Ciência \& Saúde Coletiva. Rio de Janeiro, v. 16, n. 12, p. 4.6434.652, 2011.

CARVALHO, S.R; GASTALDO, D. Promoção à saúde e empoderamento: uma reflexão a partir das perspectivas crítico-social pós-estruturalista. Ciência \& Saúde Coletiva. Rio de Janeiro, v. 13, supl. 2, p. 2.029-2.040, 2008.

CECÍlIO, L.C.O. As Necessidades de saúde como conceito estruturante na luta pela integralidade e equidade na atenção em saúde. In: PINHEIRO, R.; MATTOS, R.A. (Orgs.). Os sentidos da integralidade na atenção e no cuidado à saúde. Rio de Janeiro: Cepesc, 2001. p. 113-126.

COSTA, C.S.; BANDEIRA, M.; CAVALCANTI, R.L.A.; SCALON, J.D. A percepção de pacientes e familiares sobre os resultados do tratamento em serviços de saúde mental. Cadernos de Saúde Pública. v.27, n.5, p.995-1007, 2011.

DELFINI, P.S.S. et al. Parceria entre CAPS e PSF: o desafio da construção de um novo saber. Ciência \& Saúde Coletiva. Rio de Janeiro, v. 14, n. 1, p. 1.483-1.492, 2009.

DESLANDES, S.F. Concepções em pesquisa social: articulações com o campo da avaliação em serviços de saúde. Cadernos de Saúde Pública. Rio de Janeiro, v. 13, n. 1, p. 103-107, 1997. 
DIMENSTEIN, M.D.B. et al. O apoio matricial em Unidades de Saúde da Família: experimentando inovações em saúde mental. Saúde e Sociedade. São Paulo, v. 18, n. 1, p. 63-74, 2009.

DONABEDIAN, A. An introduction to quality assurance in health care: consumer's role. New York: Oxford University Press, 2003.

FRANCO, T.B.; MERHT, E.E. Cartografias do trabalho e cuidado em saúde. RevistaTempus - Actas de Saúde Coletiva, v.6, n. 12, p. 151-63, 2012.

JAEGGER, R.C. et al. A experiência de morar fora: avaliação da satisfação de usuários em um serviço de saúde mental. Cadernos de Saúde Coletiva. Rio de Janeiro, v. 12, n. 1, p. 2739, 2004.

MENDES, E.V. As redes de atenção à saúde. 2a ed. Brasília: OPAS, 2011.

MERHY, E.E. Saúde: a cartografia do trabalho vivo. São Paulo: Hucitec, 2002.

MINAYO, M.C.S. Análise qualitativa: teoria, passos e fidedignidade. Ciência \& Saúde Coletiva. Rio de Janeiro, v. 17, n. 3, p. 621-626, 2012.

MUNARI, D.B. et al. Saúde mental no contexto da atenção básica: potencialidades, limitações, desafios do Programa de Saúde da Família. Revista Eletrônica de Enfermagem, v. 10 ,n. 3, p. 784-795, 2008.

RANDEMARK, N.F.R. Reabilitação psicossocial de pessoas com transtorno mental no contexto da reforma psiquiátrica brasileira: representações das famílias. 2006. 270 f. Tese (Doutorado em Enfermagem Psiquiátrica) - Escola de Enfermagem, Universidade de São Paulo, São Paulo. 2009.

REINALDO, A.M.S. Saúde mental na atenção básica como processo histórico de evolução da psiquiatria comunitária. Escola Anna Nery Revista de Enfermagem. Rio de Janeiro, v. 12, n. 1, p. 173-178, 2008.

SILVA, L.M.V.; FORMIGLI, V.L.A. Avaliação em saúde: limites e perspectivas. Cadernos de Saúde Pública. Rio de Janeiro, v. 10, n. 1, p. 80-91, 1994.

SILVA, N.H.L.P.; CARDOSO, C.L. A construção de uma pesquisa fenomenológica em Edith Stein na interface Saúde Mental e Saúde da Família. In: MAHFOUD, M.; MASSIMI, M.(Orgs). Edith Stein e a psicologia: teoria e pesquisa. Belo Horizonte: Artesã, 2013b. p. 381-411.

SILVA, N.H.L.P.; CARDOSO, C.L. Contribuições da fenomenologia de Edith Stein para a atuação do psicólogo nos Núcleos de Apoio à Saúde da Família (NASF). Revista Latinoamericana de Psicopatologia Fundamental, v. 16, n. 2, p. 246-259, 2013 a.

SILVEIRA, E.R. Práticas que integram a saúde mental à saúde pública: o apoio matricial e a interconsulta. Ciência \& Saúde Coletiva. Rio de Janeiro, v. 17, n. 9, p. 2.377-2.386, 2012. STARFIELD, B. Atenção primária: equilíbrio entre necessidades de saúde, serviços e tecnologia. Brasília: UNESCO, 2002. 
TAHAN-SANTOS, E.; CARDOSO, C.L. Experiências de participantes em um Grupo de Promoção de Saúde na Estratégia Saúde da Família. Psico., v. 39, n. 4, p. 410-417, 2008. TANAKA, O.Y.; RIBEIRO, E.L. Açōes de saúde mental na atenção básica: caminho para ampliação da integralidade da atenção. Ciência \& Saúde Coletiva. Rio de Janeiro, v. 14, n. 2, p. 477-486, 2009.

WORLD HEALTH ORGANIZATION. Conferência Internacional sobre Cuidados Primários de Saúde. Declaration of Alma Ata. Alma Ata: Cazaquistão, 1978.

WORLD HEALTH ORGANIZATION. First International Conference on Health Promotion, Ottawa Charter for health promotion. Ottawa: Canadá, 1986.

\section{Nota}

${ }^{1}$ M.S. Frateschi participou da concepção do projeto; coleta dos dados; análise e interpretação dos dados; redação do artigo; aprovação final da versão a ser publicada do artigo. C.L. Cardoso participou da concepção do projeto; análise e interpretação dos dados; redação do artigo; supervisão do trabalho realizado durante as diferentes etapas; e aprovação final da versão a ser publicada. 


\section{Abstract}

\section{Mental Health in Primary Care: evaluation from the viewpoint of users}

This study aimed to investigate the evaluation made by users regarding mental health care delivered at two public health services from the primary health care network, namely a Family Health Unit and a Basic Health Care Unit. The sample comprised 13 users from both services who were identified by the teams as being mentally ill. Data were collected using the focus group technique, with one group being performed in each service. The material collected was then submitted to analysis following the qualitative approach and using the thematic content analysis. Users point to the need for qualified listening, so as to promote embracement and bonding, as well as humanized, longitudinal and comprehensive care. In conclusion, a gap is observed between the actions in mental health care and in primary health care, and the evaluation made by the users constitutes a fundamental tool for filling this gap, since users provide essential information for the consolidation of new ways of acting in health care.

> Key words: Mental Health; Primary Health Care; Family Health Program; Health Services Evaluation. 